wave-form observed on the right side is associated with pace-maker activity.

Thus an electric wave-form which is synchronous with the uterine contraction can be demonstrated at some time during developing labour. The waveform is dominantly monophasic in certain areas, and diphasic elsewhere. In the area of monophasic wave-form, higher-frequency components may be seen which may be related to the focus of activity.

On the basis of the available electrical evidence, the following hypotheses may be suggested : (1) The human uterus in labour behaves electrically as a single-chambered, auricle-like structure. (2) The contractions of the human uterus under the given conditions are controlled by a single pace-maker. (3) Under ordinary conditions, this pace-maker seems. to be on the right side. (4) Excitation of the uterus is basically radial in normally developing labour.

This research was supported by a grant-in-aid from the United States Public Health Service, $R G-4462$.

Medical Center,

S. D. LARKS

University of California,

Los Angeles 24,

California.

Sept. 29. 'Steer, C. M., and Hertsch, G. J., Amer. J. Obst. Oynec., 59, 25 (1950),
Levy-Solal, E., Morin, P., and Zacouto, F., Presse Med., 60, 1335 (1952).

2 Larks, S. D., Fed. Proc., 15, 376 (1956). Larks, S. D., Assali, N. S. Morton, D. G., and Selle, W. A., J. App. Phyziol., 10, 493 (1957)

${ }^{3}$ Wilson, F. N., Macleod, A. G., and Barker, P. S., Univ. of Mich. Studies, Scientific Series, 18, 58 (1933), as reproduced in the Appendix to D. Sodi-Pallares "New Bases

- Van Der Kooi, M. W., Durrer, D. Van Dam, R. Th., and Van Der Tweel, L. H., Amer. Heart J., \$1, 684 (1956).

\section{Shaking of Honeybee Queens prior to Flight}

ReCentuy Hammann ${ }^{1}$ has published a description of the way in which worker honeybees push, pull and shake their unmated queen before she leaves the hive on her mating flights. After each of these flights the 'attacks' subside somewhat, but they increase in frequency once again before the next flight, only ceasing finally when the queen commences egg-laying. Hammann lists several types of movement which the workers make around the unmated queen, and of these she found that shaking was by far the most frequent. This movement hes been described previously ${ }^{2,3}$ (although no evidence as to its function has been put forward), and consists basically of a rapid vertical vibration of the worker's body lasting 1-2 sec. while its legs grasp either the queen or another worker.

Hammann states that she has never seen an established queen shaken by the workers, and I would agree that for much of the year the queen is not normally shaken. The important exception, apart from the period between emergence and egg-laying, is during the swarming season. At this time the colony makes extensive preparations which culminate in the departure of the mated queen with the swarm ${ }^{3}$, and during this period the queen may very frequently be shaken, as shown in Fig. 1, in which is recorded the number of times per hour the workers of a small but otherwise normal colony in an observation hive shook their queen. Observations began on April 11 and the earliest record of

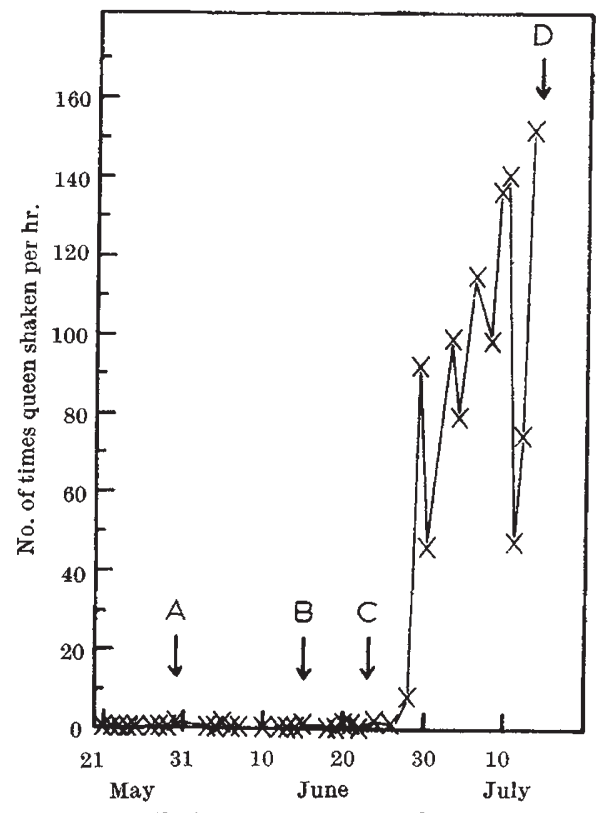

Fig. 1. Shaking of the honeybee queen by the workers. $A$, First record of shaking ; $B$, first drone eggs laid; $C$, first queen cup

shaking was on May 30, but it was only after the formation of the first queen cup on June 23 that shaking reached any major proportions. From then on the frequency rose rapidly to a peak on July 13, when the queen left the hive with the swarm. A similar sequence of events was observed, though in rather less detail, in two other colonies.

From the coincident occurrence of swarm preparations and the shaking of the queen it would seem evident that the two events are closely connected; furthermore, it is surely not by chance that the only times when the queen is shaken are before she flies out from the hive, either with the swarm or on a mating flight. It would therefore appear that shaking is a mechanism in some way preparing the queen for flight. It may also be assumed that the incidence of the shaking of the queen is governed at least partly by an internal (colony) factor since it occurs at definite stages in colony development. It may also possibly be influenced by external factors such as weather conditions.

As already mentioned it is known that workers may shake other workers, but little information apart from a description of the process is available on this subject. It is hoped shortly to publish elsewhere the results of a series of observations on the shaking of workers, but at present it can be stated that, in contrast to the shaking of the queen, this occurs relatively frequently throughout the year. Moreover it, too, appears to have a connexion with flight activity.

\section{Delia Allen}

Bee Research Department,

North of Scotland College of Agriculture, Marischal College,

Aberdeen.

Sept. 9.

I Hammann, Eleonore, Insectes sociaux, 4, 91 (1957).

2 Taranov, G. F., and Ivanova, L. V., Pchelovodstvo, 2, 3, 35 (1946).

Istomina-Tzvetkova, K. P., ibid., 9, 15 (1953). Schick, W. Z. vergl. Physiol., 35, 105 (1953).

${ }^{3}$ Allen, M. Delia, Brit. J. Anim. Behav., 4, 14 (1956). 